Int. J. Speleol. 20 (1991): 37-45

\title{
Revision of the genus Troglophilus (Orthoptera, Rhaphidophoridae) in Crete, Greece
}

\author{
Dimitrios Kollaros, Kaloust Paragamian and Anastassios Legakis *
}

\section{SUMMARY}

The genus Troglophilus (Orthoptera, Rhaphidophoridae) from Crete is revised using new data from specimens collected recently. The three previously reported species are considered to be only one, $T$. spinulosus, on the basis of morphological, ecological and distributional similarities. The species is more fully described and notes are given on its ecology.

\section{INTRODUCTION}

The genus Troglophilus has been considered to be represented in Greece by at least 6 species, 4 of them endemic (Willemse, 1984).T. cavicola is known from Austria, northern Italy, western Yugoslavia and central Greece. T. neglectus is known from Austria, western Yugoslavia and Greek Makedonia. T. lagoi is known only from Rhodos island. T. spinulosus, $T$. roeweri and $T$. petrochilosi are known only from Crete. In addition to these six, a new species of Troglophilus has recently been found on Santorini island (Beron, 1986).

As mentioned by Willemse (1985), the systematics and distribution of most cavernicolous orthopteran species in Greece have many problems as very few individuals, and in some cases subadults, have been used in descriptions. This has been pointed out by us in a previous paper (Kollaros et al., 1987) on the Cretan cavernicolous Orthoptera. In the present paper we provide more data on the genus Troglophilus in Crete and conclude that it is represented by only one species ( $T$. spinulosus). We provide additional description of syste-

* Dept. of Biology, Univ. of Crete, 71409 Iraklion, Greece 
matic characters where needed and make some comments on its ecology.

\section{LITERATURE REVIEW}

The first Cretan species of Troglophilus was described by Chopard (1921) under the name T. spinulosus. The description was based on a subadult male specimen collected by D. Bate in 1904 from cavities near the monastery of Gonia (Chania dept.).

Werner (1927) described a second species, $T$. roeweri, from two males and females (adults?) found in "Arkalospilios" cave in western Crete. The existence of this species was debated by Chopard (1957) who claimed that it was the immature of $T$. spinulosus. BoudouSaltet (1978) described the female of $T$. spinulosus from a specimen found in "Sendoni" cave (Iraklion dept.) and a third species of Troglophilus (T. petrochilosi) from 1 male and 2 females, all adults, found in "Diktaion Andron" cave (Lasithi dept.). She supported the existence of $T$. roeweri and mentioned that the Troglophilus species are distributed as follows based on the then available data: $T$. roeweri in western Crete, $T$. spinulosus in central Crete and $T$. petrochilosi in eastern Crete. In our previous paper (Kollaros et al., 1987) we noted that there was a misunderstanding with the Troglophilus distribution. Bate had collected in 1905 the T. roeweri specimens from the monastery of Gonia (Chania dept. - western Crete) and not from the village of Gonia (Rethymnon dept. - central Crete) (Bate, 1913). Studying 30 characters of 150 samples, we concluded that two species probably exist in Crete, a "small" one and a "big" one, both widely distributed. At all events, the question whether the "small" species, corresponding to $T$. roeweri, was an immature $T$. spinulosus had not been answered.

\section{METHODS}

During the last two years, more than 70 caves, cavities and canyons from all over Crete have been visited in search for Troglophilus species and some of them have been sampled several times throughout the year. Troglophilus specimens were found in 14 localities (Fig. 1). Those without clear sexual characteristics such as 


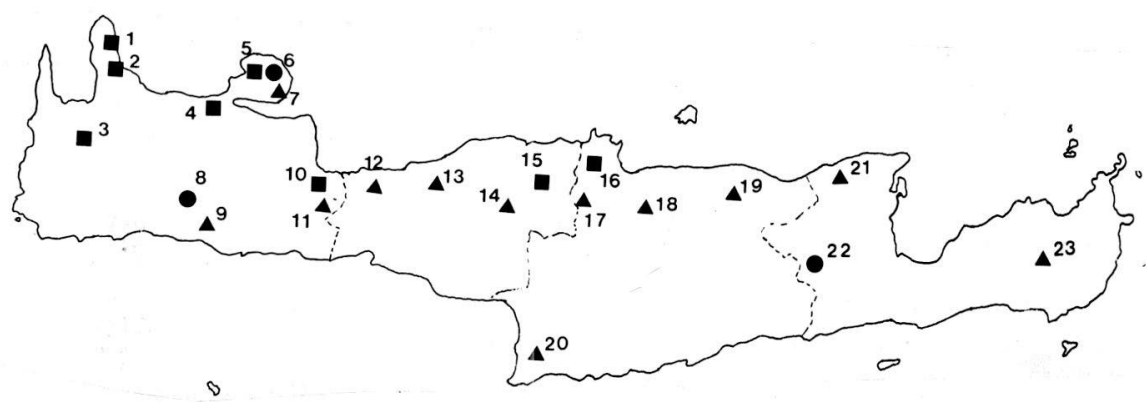

Fig. 1 - Map of Crete showing locations where Troglophilus specimens have been collected. (square: unconfirmed old records, circle: confirmed old records, triangle: new records) 1: Ellinospilios, 2: Moni Gonias, 3: Ag. Sofia, 4: Hania, 5: Achyrospilios, 6: Moni Gouvernetou, 7: Farangi Gouvernetou, 8: Tzani, 9: Samaria, 10: Georgioupoli, 11: Kourna, 12: Gerani, 13: Myloi, 14: Psiloritis, 15: Sendoni, 16: Arkalospilios, 17: Gonies, 18: Ag. Irini, 19: Ag. Paraskevi, 20: Agiofarango, 21: Milatos, 22: Diktaion Andron, 23: Mikro Katafygi.

subgenital plates and ovipositors, approximately 20 specimens, were not included in the analysis. Nearly 200 specimens have been collected in total, while for their study, 30 characters were used in total (Table 1). These characters have been used in the past to describe the three species. For statistical analysis we used the SPSS statistics package of the University of Crete Computing Center.

\section{RESULTS AND DISCUSSION}

The study of the "big" type of Troglophilus showed that we definitely cannot classify it in two different species. The characters used by Chopard and Boudou-Saltet to separate T. spinulosus and $T$. petrochilosi are very variable within the same individual. The characters used by Boudou-Saltet to distinguish $T$. petrochilosi were: a. A more light coloration; b. Keel on the 7th and 8th tergite only; c. Ovipositor less acute with only one apical tooth on the inferior valves; d. Subgenital plate of the female not bilobe at the end; e. Proportions between body length, posterior femur and ovipositor 20 $\mathrm{mm}, 18-19 \mathrm{~mm}$ and 8-10 $\mathrm{mm}$ for T. petrochilosi and $23 \mathrm{~mm}, 23.5 \mathrm{~mm}$ and $12.5 \mathrm{~mm}$ for $T$. spinulosus. In the "big" specimens collected by us: a. The coloration was variable within the same population; $b$. The shape of the keels was also variable within the same population; c. The shape of the ovipositor was similarly acute in all specimens 
Table I - Characters used in the identification of Troglophilus species. (*: characters used in principal component analysis)

$3 \mathrm{~d}$ to 5 th palp segment ratio*

Keel of tergites

Lobes of the 10th tergite

Number of spines on the upper side of the right front tibia

Number of spines on the upper side of the left front tibia

Number of spines on the under side of the right front tibia

Number of spines on the under side of the left front tibia

Number of spines on the under side of the right middle femur

Number of spines on the under side of the left middle femur

Number of spines in the middle part of the inferior internal edge of the hind right femur

Number of spines in the middle part of the inferior internal edge of the hind left femur

Number of spines on the external upper side of the right hind tibia

Number of spines on the external upper side of the left hind tibia

Number of spines on the internal upper side of the right hind tibia

Number of spines on the internal upper side of the left hind tibia

Number of spines on the external under side of the right hind tibia

Number of spines on the external under side of the left hind tibia

Number of spines on the internal under side of the right hind tibia

Number of spines on the internal under side of the left hind tibia

Simple and apical spurs of metatarsus of the hind right leg

Simple and apical spurs of metatarsus of the hind left leg

Apical lobes on the edge of the female subgenital plate

Number of teeth on the internal valves of the ovipositor *

Number and location of the last teeth of the internal valves of the ovipositor

Length of body *

Length of the hind right femur *

Length of the hind left femur *

Length of the hind right tibia *

Length of the hind left tibia *

Length of ovipositor *

and the last two teeth of the inferior valves were either converging, completely separate or forming a bifurcate tooth within the same populations and the same specimens (Fig. 2); d. The subgenital plate's apex of the female varied from monolobe to bilobe; e. The body length of the specimens from caves where $T$. spinulosus had been recorded, varied from 17-22 mm, the posterior femur 19-21 mm and the ovipositor from $8-10 \mathrm{~mm}$. Therefore, the "big" type of Troglophilus must belong to one species. 


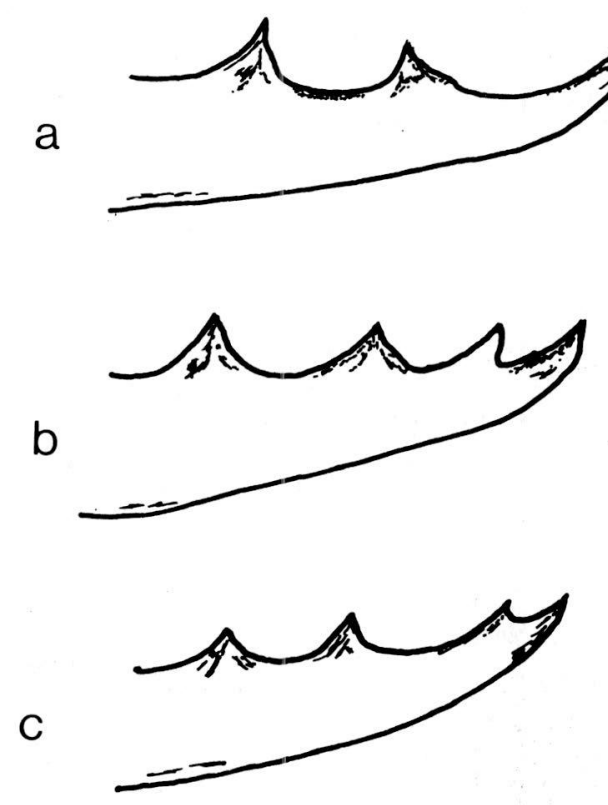

Fig. 2 - Inferior valve of female $T$. spinulosus ovipositor. a: separate apical teeth. b: converging apical teeth. c: bifurcate apex.

In order to analyse quantitatively all the characters from all the specimens, a principal component analysis was carried out. Before this, a Kruskal-Wallis non-parametric analysis of the variance of all characters according to caves was carried out in order to eliminate the characters that were equally variable within populations and between populations. In this way, 22 characters were rejected because they either showed no variation, had similar variation within all populations or were very subjective. The principal component analysis of the remaining characters showed that the three principal axes that accounted for $97.5 \%$ of the variation were related to the length of the hind femur, the length of the ovipositor and the number of teeth respectively. According to these three characters all of which are related to length, two types can clearly be distinguished (Fig. 3). One has no teeth on the ovipositor, the length of the ovipositor ranges from 3-4 $\mathrm{mm}$ and the length of the hind femur ranges from 15-16 $\mathrm{mm}$. The other has 8-11 teeth on the 


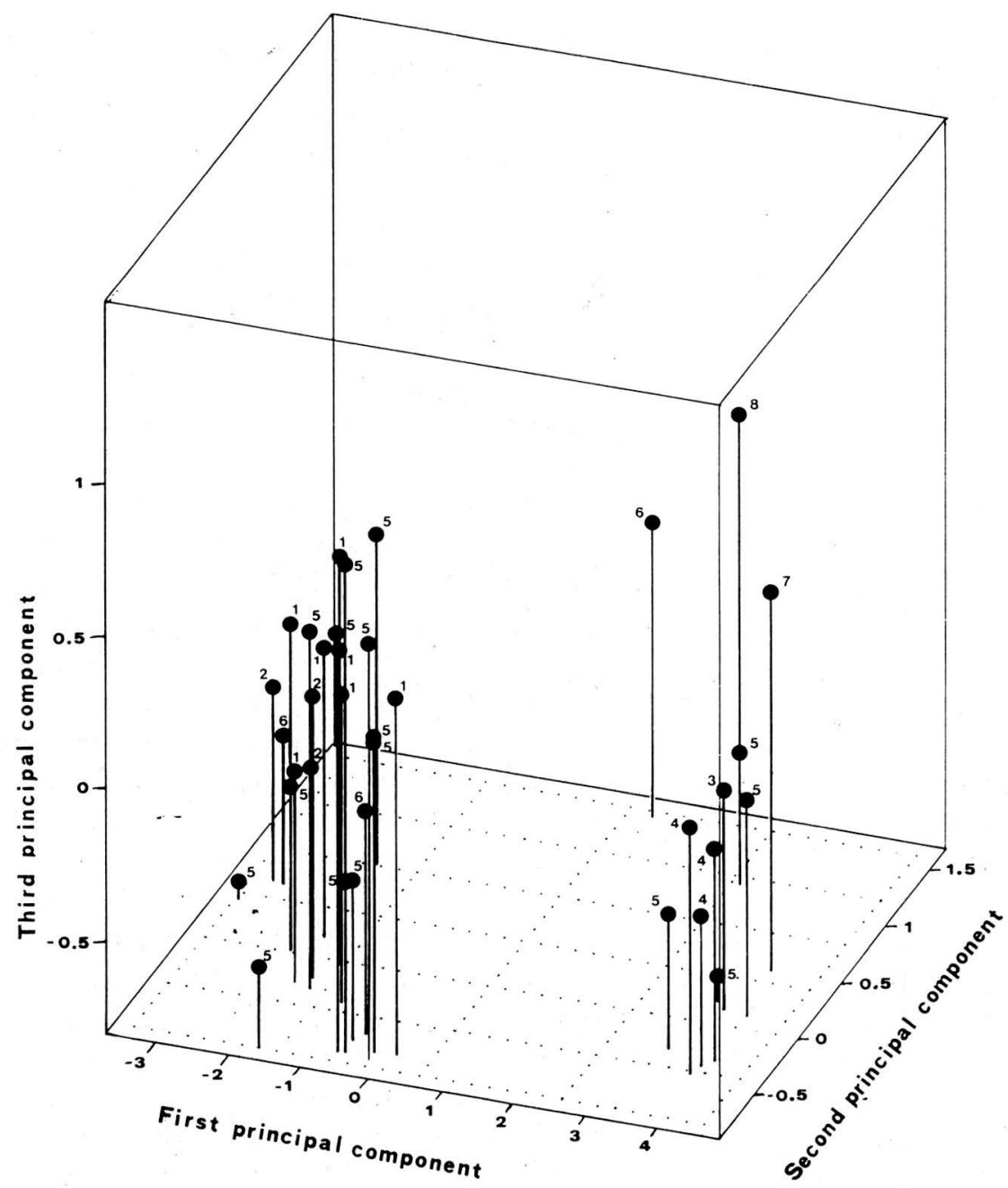

Fig. 3 - Principal component analysis of female $T$. spinulosus specimens. Left group: immatures, right group: adults. (1: Kourna, 2: Farangi Gouvernetou, 3: Samaria, 4: Milatos, 5: Ag. Paraskevi, 6: Ag. Irini, 7: Tzani, 8: Diktaion Andron).

ovipositor, the length of the ovipositor is $8-10 \mathrm{~mm}$ and the length of the hind femur ranges from 19-21 mm.

These two types had never been found in the same cave and this supported the two species hypothesis. An interesting point is that in 
the localities where the "small" type occurred, there were always very small individuals which had been considered as its immatures. In contrast, no such immatures where found in localities were the "big" type occurred.

We recently found both types coexisting in two caves: the cave of Milatos and the cave of Agia Paraskevi near Skoteino. The last cave supports, as far as we know, the largest Troglophilus population in Crete.

The gap in some characters between the "small" and the "big" type can be explained by the presence of one or more moults. For example, the $4 \mathrm{~mm}$ ovipositors have no teeth, the $7 \mathrm{~mm}$ ovipositors have rudimentary teeth and the $8-10 \mathrm{~mm}$ ovipositors have fully grown teeth. Also all populations of the "big" type were very small while the "small" type populations were always numerous. The differences between the two types concern characters associated with size. The other characters, such as shape of subgenital plate which is an important character in separating other species, are the same. The toothless ovipositor of the "small" type is unsclerotized, a characteristic that is associated with individuals that have not reached their final moult (Chopard, 1965). The above facts, along with the overlapping distribution and the immature-like characteristics of the "small" type allow us to suggest that there is only one species of Troglophilus in Crete: Troglophilus spinulosus Chopard, 1921.

\section{SUPPLEMENTARY DESCRIPTION}

We provide a supplementary description of $T$. spinulosus in these characters where differences or variation were found. All the other remain as described by Chopard and Boudou-Saltet.

Adult: The length of body, hind femur and hind tibia are 17-22, 19-21, and 21-24 mm respectively. The $3 \mathrm{~d}$ to 5 th palp segments ratio varies from 2.8:3.8 to $3: 3.5$. Number of spines on the upper side of the front tibia: 9-11. Number of spines on the under side of the middle femur 3-11. Number of spines on the middle part of the inferior internal edge of hind femur: 3-8. Number of spines on the external upper side of the hind tibia: 53-77. Number of spines on the internal upper side of hind tibia: 52-68. Number of spines on the 
external under side of hind tibia: 18-25. Number of spines on the internal under side of hind tibia: 11-16. Simple and apical spurs of the metatarsus of hind leg.: $4+1$ to $8+1$. The 6 th, 7 th and 8 th tergites keeled backwards with a more or less angular prolongation in the back edge. Subgenital plate of male big, bilobe with cerca rather short and flattened in the base of the external side. Subgenital plate of the female triangular, monolobe or bilobe on the apex. Shape of ovipositor acute. Length of ovipositor $8-11 \mathrm{~mm}$. The apical teeth of the internal valves can be converging, completely separate or bifurcate, while any combination of these can be found in the same specimen.

\section{ECOLOGICAL NOTES}

T. spinulosus is found in the entrances of caves or similar places such as cavities and under big rocks. It is active during the night, remaining hidden in small holes, under stones or among litter during the day. For this we can characterize it as trogloxene. It can coexist with Dolichopoda paraskevi and Discoptila lindbergi in the same cave because they occupy different niches (Kollaros et al, 1987). Adult individuals are found on the entrance walls while immatures on the floor.

As mentioned before, in only two cases did we find adults and immatures coexisting. This could be a result of the differences in some characteristics of the cave entrances. The entrance of the cave Agia Paraskevi is a doline full of stones and litter with a soft substrate (Paragamian \& Legakis, 1986). It is located in a large overgrazed landscape and thus is the only shelter for Troglophilus which limited there, develops a large population. In contrast, Milatos and all the other caves where $T$. spinulosus adults were found, have a litterless, stoneless and hard substrate entrance. We might suppose that it lays its eggs in soft substrate and all immatures take advantage of litter and stones to hide themselves during the day. Thus, when these do not occur, adults are forced to search for suitable places away from the entrance for oviposition. This may be one of the reasons for which immature individuals were not found in caves with hard substrate as in the case of Milatos where immatures were found away from the entrance. 


\section{BIBLIOGRAPHY}

BATE, D. 1913. The caves of Crete. In: A. Trevor-Battye, Camping in Crete. pp. 239-253.

BERON, P. 1986. Results of the study of the cave fauna of Greece. Biol. gallo-hellen. 12: 125-131.

BOUDOU-SALTET, P. 1978. Sur les Troglophiles (Orth. cavernicoles) de Gréce. Bull. Soc. Hist. Nat. Toulouse 114 (1-2): 115-121.

CHOPARD, L. 1921. Description d'une espèce nouvelle du genre Troglophilus. Bull. Soc. ent. Fr. 1921: 147-151.

CHOPARD, L. 1965. Ordre des Orthoptères. In: Traité de Zoologie. P.P. Grassé (ed.). Tome IX, pp. 617-722.

KOLLAROS, D., K. PARAGAMIAN, A. LEGAKIS. 1987. Notes on the systematics of cavernicolous Orthoptera of Crete. Biol. gallo-hellen. 13: 137-140.

PARAGAMIAN, K., A. LEGAKIS. 1986. Ecological and faunistic investigations of cave Ag. Paraskevi near Skoteino (Crete, Greece). Rapp. Comm. int. Mer Medit. 30 (2): 90 .

WILLEMSE, F. 1984. Catalogue of the Orthoptera of Greece. Fauna Greciae I. Hell. zool. Soc., $275 \mathrm{pp}$.

WILLEMSE, F. 1985. A key to the Orthoptera species of Greece. Fauna Graeciae II, Hell. zool. Soc., 288 pp. 